\title{
Home Environment and Stressful Life Events On Child Depression
}

\author{
Nur Alina Saidah \\ University of Muhammadiyah Malang \\ nuralinasaidah@gmail.com
}

\begin{abstract}
Many of the children who are depressed have a life in the home environment that is less supportive of mental health. Depression is the reduction of energy and passion, feelings of guilt in him, lack of concentration, loss of appetite and their thoughts of death and suicide is accompanied by changes in the level of activity, cognitive ability and disturbances in sleep. A child's home environment greatly affects the mental state and personality of the child. Data survey has shown an increase in depression in children from year to year and many cases that mention depression experienced by children because their home environment, especially the attitude of the parents. Children who are depressed certainly experience various stressful life events. Stressful life events are events that dilaami by someone, resulting in stress and can continue until the stage of depression. This study aims to determine the shape of the home environment can be one factor in the form of depression and stressful life events that are often experienced by depressed children. The method used in this research is the study of literature. Results from this study is that the home environment is most prevalent in children depression is a home environment where the child is experiencing social isolation as well as the deprivation of rights of the child. The stressful life events often daialmi child depression is the presence of family violence as well as the loss of family members. The conclusion from this study is that children with a family environment who get social isolation and deprivation susceptible to depression or aggravate mental conditions and children who are depressed most experienced stressful life event such as domestic violence and the loss of family members.
\end{abstract}

Keyword: Enveriomental, stressful life, child, depression

\section{INTRODUCTION}

Based on the report of the World Health Organization (WHO) reported that a mental disorder was ranked fourth in the world's health problems. Among the mental disorders that occur, the largest note is a mental health disorder associated with depression. Depression is a common psychiatric disorder classified, some people think depression is a natural reaction to the effects of an event and some people assume that depression is an illness that is quite heavy. Depression can be influenced by the people around him, in addition to their descendants aspects of depression can also be caused by social factors and the environment (Molavi, 2006).

This depressive disorders can cause severe suffering. Depression is a problem in public health. Medical expenses are very large and if not treated can occur very bad thing because it can lead to serious disturbances in social functioning, quality of life, and death due to suicide.

Depression can happen to anyone regardless of age, including children. They will be susceptible to depression to a stressor developments. There are no exact figures on the incidence of depression anak.Menurut WHO, in $20 \%$ of children who have experienced problems of mental disorder, the diagnosis of recurring depression with incidence rates ranging from $0.2 \%-17 \%$. National Institute of Mental Health to get the prevalence of depression children aged 9-17 years more than $6 \%$. Depression is often increased when children approach the age of puberty, especially at the age of 7-13 years and tend to recur (Merikangas, 2009).

Research carried out in Yemen Jordan mentions the prevalence of children who are depressed in the city is $5.9 \%$ which fall into the category of major depression and no significant results that show differences in prevalence between men and women. Results of interviews conducted at the research shows that one factor that raises the risk of depression is a family environment to be around for the child (Tonnus, 2011).

Depression is closely connected with the reduction of energy and passion, feelings of guilt in him, lack of concentration, loss of appetite and their thoughts of death and suicide is accompanied by changes in the level of activity, cognitive ability, speaking, disorders of sleep and other biological rhythms. Depression can occur in men and women and in all age groups including children, and has been reported 10-64\% depression occurs among children and young people (Beniwal, 2016). In a few studies have been done that the prevalence of depression in children in some areas is high.

Depression does not only occur in adults. Children and adolescents may also experience depression, which is actually a disease that dapatdiobati. Depression is defined as an illness when distress and disrupt the activities of a child or teenager to serve normal.Sekitar $5 \%$ of children and adolescents in Indonesia suffer from depression at some point in time. Children under pressure, at the time of learning in school, are at a higher risk for depression. Depression also tends to exist in his own family. (haryanto, 2015) 
Children and adolescents often reported episodes of sadness and tears, feeling apathy, insomnia, fatigue, and lack of appetite. They also have thoughts of suicide and even tried to commit suicide. But depression in children also have different characteristics such as refusing to go to school, fearing the death of a parent, and tied to the parents. Academic problems, physical complaints, and even hyperactivity can be sourced from depression are not aware. Nolen-Hoeksema found moderate depression can last for several years and greatly affects school performance and social functioning (Nevid, 2005)

Depression that occurs in childhood and adolescence are closely related to the family situation. Research shows that the development of children and depression in a child affected by the family situation (Sander and MCCharty, 2005). From baby Parents play an important role in the life of a child, with his parents bersoasialisasi emotionally, mentally, and physically. With their relationship or an unhealthy family environment may negatively impact on the child one of them is depression in the child.

Family environment is very active in the mental health of a child. The study that was done to report that the family environment is not good having a fairly high risk factor in causing depression in children. Study conducted in Brazil stated that the child's environment with less harmonious family and often see violence and strife in the family is a cause that can cause a child to become depressed. (Joviana, 2012). Children who are often penalized when they are at home and they were not given full rights by the family environment is also the potential to make children depressed. (Beniwal, 2016).

Children who are depressed may affect morbidity, mortality, and function for life. Individuals, families, and the environment are factors that have been documented as psychosocial risk factors for depression in children, especially in domestic violence, with the result of inadequate support for children, cohesion in the family is low, and poor communication (Joviana, 2012)

children who are depressed to see some events experienced, in which the incident was a serious incident according to the child and make the child's condition falls within the category of stressful. Specific life events correlated with perceived stress levels. Many potentially stressful events that can be measured, because when surveyed, most people judge a particular life event as the most exciting or the most stressful.

In the study conducted by Beniwal in Rajakastan in 2016, researchers held peelitian to make a comparison between depressed children with children who did not experience depression related to stressful life events they had experienced. Results of the study says that Naakdepressed experienced more stressful life events in his life than children who do not have depression.

With the description described earlier, researchers interested in conducting research to determine the condition of the home environment as if possessed by children depression and know stressful life event such as whether the most commonly experienced by children who are depressed, so that we can know the home environment that children most at risk to become depressed and know stressful life events are often found by children depression. The benefits to be gained from this research is to prepare preventive measures to reduce the risk factor of depression in children.

\section{LITERATUR}

\section{Child Depression}

Depression is an emotional condition that is usually characterized by profound sadness, feelings of meaning and guilt, withdrawal from others, unable to sleep, loss of appetite, sexual desire, and interest and pleasure in usual activities dilakukan.Sebagaimana most of us occasionally experience anxiety. Depression is often associated with a variety of other psychological problems, such as panic attacks, substance abuse, sexual dysfunction, and personality disorders (Davison, 2006).

Concentrating personality becomes very tiring for people who are depressed. They can not easily understand what they read and what people say to them. Each moment becomes very heavy and their heads continue to be filled with thoughts of self-blame sendiri.Orang who are depressed may neglect hygiene and personal appearance and complained of various symptoms-somatic without obvious physical disorder (Davidson, 2006). Very discouraged and did not really have the hope and initiative, they always feel worried, anxious and pessimistic most of the time.

Rathus (1991 in Lumongga 2009) suggests people with depression generally suffers covering emotional state, functional motivation, and cognition. According to Atkinson (1991 in Lumongga 2009) depression as a mood disorder characterized by there was no hope and heartbreak, helplessness excessive, unable to take a decision to start an activity, incapable of concentration, did not have the spirit of life, always tense, and attempted suicide. Thus we can say that depression is a mood disorder that is characterized by a deep melancholy and sadness, and continuing until the loss of vitality of life and a sense of hopelessness.

Derjadinya causes of depression based on Cognitive Theory which considers thinking processes as factors causing depression theory Aaron Beck (Davison, 2006). The central thought is that people who are depressed have a feeling like that because they stray thoughts in the form of a negative interpretation. Cognitive theory believes that people who adopt a negative way of thinking that has a greater risk to become depressed when faced with stressful life experiences or disappointing. Beck looked negative concepts about self and the world as a mold mental or cognitive schemes adopted during childhood on the basis of learning experiences early days. Children can discover that there is none that they do that pretty well so as to please parents or their teachers. As a result, they would think of themselves as people who were basically incompetent and their future looked bleak. These beliefs can make them become more sensitive in the next life so 
interpret any failure or disappointment as a reflection of something basically wrong about themselves. Small disappointments and personal failure to be "exaggerated beyond the proportions." Even a small disappointment can be destructive waves or total defeat, which can lead to depression (Nevid, et al., 2005).

The tendency to exaggerate the importance of minor failure is an example of an error in thinking is called Beck as cognitive distortions. He believes that the cognitive distortions forming stages for depression in the face of personal loss or negative life events. The cognitive triangle of depression according to Beck are as follows:

1. Negative view of themselves, which saw themselves as individuals who are not valuable, full of shortcomings, unlovable, and lack the skills to achieve happiness.

2. Negative views about the environment, the environment looked as imposing excessive demands or give insurmountable obstacles, which continue to cause failure and loss.

3. Negative views about the future, which looked at the future as there is no hope and believe that he did not have the power to change things for the better. These people's expectations about the future are the continuing failure and sadness and difficulties that never ended.

The cause of the next depression is genetic and family factors indicate that the number of risk among firstdegree family members of individuals with major depression (unipolar) estimated to be 2 to 3 times compared with the general population. Figures alignment of approximately $11 \%$ in dizygotic twins and $40 \%$ in monozygotic twins. Genetic influence on depression is not mentioned specifically, only mentioned that there is a decrease in durability and ability to respond to stress. The aging process is individualized, so think about the sensitivity of a person against the disease is genetic (Lesler, 2001).

The cause further form of psychosocial factors that influence depression include: life events and environmental stressors, personality, psychodynamic, repeated failure, teorikognitif and social support. Stressful life events cause more often precedes the first episodedisorder. of mood of the next episode Clinicians believe that life events play a major role in depression, other clinicians state that life events have only a limited role in the onset of depression. The most environmental stressors associated with the onset of a depressive episode is the loss of a spouse. Acute psychosocial stressor, such as losing a loved one, or chronic stressors, such as financial problems are longstanding, interpersonal relationship difficulties, security threats can cause depression (Kaplan, 2010).

Children who experience depression also are likely to lose the spirit, passion, or interest in daily activities. In addition to the case study, children can also turn into lazy to do the game or sport that usually they do it with joy. In fact, normally a child has a soul full of energy and vigor. However, the child will tend to be depressed and lethargic no energy at all. Children who suffer from depression also tend to be more easily depressed, crying, or even angry with things that seem trivial

The criteria according to DSM V, features of depression are as follows:

Five or more of the following symptoms are, at least in two weeks, and shows a change in function. At least one of these symptoms should exist, namely (1) affective depressive or (2) loss of interest or pleasure. Should not include symptoms that are clearly due to a general medical condition or hallucinations or delusions that are not in harmony with themood.

1. moodDepressedthat occurs almost all day, almost every day, which is indicated either by subjective report (eg, feeling sad or empty), or which can be observed by others (eg, visible tears). In children or adolescents, mood. can be irritable

2. Decreased interest or pleasure

3. meaningful weight loss

4. Insomnia or hypersomnia nearly every day.

5. Psychomotor retardation nearly every

6. Weary or not powered almost every day.

7. A sense of worthlessness or excessive guilt

8. Reduced ability to think or concentration, hesitation, almost every

9. Repeated thoughts of death

\section{Home Environment (Environment Family)}

The family is the social unit of the simplest of human life. Its members consist of the father, mother, and child. For children, the family is the first social environment that is familiar. Perhaps it is difficult to ignore the role of the family in education. Children from infancy to school age have a single environment that is family. Therefore Gilbert Highest states that habit among children was partly shaped by family education. Since from waking up to going to sleep again, kids accept the influence of family education. (intercession, 2008)

The family basically have the following functions:

1. Guidance values and religious and cultural norms.

2. Provide support affective, be a relationship of warmth, love and be loved, caring and cared for, provide motivation, mutual respect, and others.

3. Personal development, such as the ability to control both the mind and the emotions themselves, know themselves and to others, the formation of personality, carry out the roles, functions and responsibilities as a member keluaraga, and others.

4. Planting awareness of the obligations, rights and responsibilities of the individual towards himself and the environment in accordance with provisions and norms prevailing in society.

Achievement of the functions of this family will form a community of qualified and become an environment conducive to the development potential of every member of the family.

The child will grow and develop properly and have a mature personality if nurtured and raised in a family environment that is healthy and happy. Personality notion, mental health is all human habits are gathered in 
him, which is used to react and adapt to any stimulus, whether arising from the environment (the external world) and which comes from itself (the world inside), so that the patterns and habits is one functional unity that is typical for that individual (Jalaluddin, 2008).

Dr. KS Mishra develop Home Environment Inventory, which in her there are 10 dimensions or type of home environment, namely:

1. Control

It shows the atmosphere autocratic many restrictions given to children by parents to discipline

2. Protective

It implies the prevention of behavioral independent and extension of care Infantile

3. Punishment

Parents always give punishment to children setiak times children do not want parents

4. Conformity

It shows the direction of a parent, a command or commands that are expected to boys or girls to comply with the act. It refers to a request to work according to the wishes and expectations of parents.

5. Social isolation

It shows parents who do not allow their children to mix with other children.

6. Choice

Parentsgives gifts or rewards each time the child does something good or expecting parents.

7. Deprivation of Rights of

Parents do not give rights owned by his son, the parents tend to do what they want

8. Compassionate

Parents give enough affection for her son.

9. Rejection

It shows the unfriendly atmosphere that includes excessive criticism, individual comparison, refusal to pay attention, do not care about the welfare of children and do not have the right to express feelings.

10. Permissive

Parents always give any permission to his son to do anything (too easy untukmemberikan permission)

\section{Stressful Life Events}

Life events are the events in the life of someone who permunculannya demand / an indication of significant changes of the pattern of life that is being executed individuals. Can be referred to as a person's life journey with a different experience on each individual resulting in the behavior of the display at this time. Genesis during his life reflect changes in the behavior of typical development in each individual and are made in a framework.

Theoretically life events can be defined as an event in the life of someone whose occurrence demand or an indication of significant changes in the pattern of life that is being run by an individual (Klaus Riegel - critical Evets).

The results of the research that major life events (eg, death of a spouse, divorce) to give effect to the state to individuals, namely the power to change their personality. This time how many people might consider a live event as a high stress. While others saw the incident as a challenge. When one considers the incident severe and stressful, then it is included in the stressful life event that happened (Gregory, 2010).

It is important to consider the socio-cultural circumstances that occur in the event of life. For example, divorce of parents may occur due to stress after years of marriage.

As for some of stressful life events are included in the instrument created by Kenner there are 43 kinds of events. Some examples are the death of a family member, perceraiaan parents, schools displacement, conflict with people nearby, has a fairly severe illness, and other sebaigainya.

\section{METHOD}

In conducting scientific research should be carried out systematic preparation techniques to facilitate the steps to be taken. Similarly, the author in this study, the first step is to conduct a study of literature in books, journals, and research has been done with regard to which discusses home environement, stressful life events anddepression.

\section{RESULT}

Based on the description above can be concluded that the home environment (home environment) effect on the mental health of children, especially if the home environment is not good that would result in or exacerbate depression child. Similarlyliefe stressful events experienced by children depression more than normal children in general. The stressful life events that are often encountered by children whose depression is the loss of a family member.

\section{REFERENCES}

Avanci, Joviana., Assis, S., Oliveira, R., \& Pires, T. (2012). Childhood depression. Exploring the association between family violence and other psychosocial factors in low-income Brazilian schoolchildren. Child and adolescent psychiatry and mentalhealth, 6(1), 26.

Beniwal, N., Verma, GK, Chahar, CK, \&Verma, KK (2016). To study the prevalence of depression and effect of home environment on depression among school going children. International Journal of ContemporaryPediatrics, 3(3), 988992.

Feist, J. and Gregory J. Feist. (2008). Theories of Personality (Sixth Edition). Yogyakarta: Student Library.

Haryanto, et al. (2015). Detection System Disorders Depression in Children and Adolescents. Scientific Journal of IndustrialEngineering.Vol. 14. No. 2 
Imilia, LS, and Devi, V. 2007. Factors Affecting the Prediction of Bond Ratings Manufacturing Companies Listed in Indonesia Stock Exchange, the Journal of the National ProceedingSeminar SMART Management, Bandung

Kaplan HI, Sadock BJ, Grebb JA 2010. Synopsis of Psychiatry Volume2.Translation WidjajaKusuma. Jakarta: Script Binarupa

Lubis, NamoraLumongga. (2009). Depression PsychologicalReview.Jakarta:

KencanaPrenada Media Group

Lesler, Zayas, C., 2001.Comprehensive GeriatricAssessment.USA: McGraw Hill Companies,

Davison, GC \& Neale JM (2006). Abnormal Psychology. Jakarta: PT. King GrafindoPersada

Merikangas, Kathleen R., Erin F. Nakamura, B, \& Kessler, C., Ronald PhD. (2009). Epidemiology of mental disorders in adolescentschildrenand. US National Library of MedicineNational Institutes ofHealth. March; 11 (1): 7-2.

Molavi, P. \&Karimollahi, Ann M. (2006) Prevalence of depression in Ardabil medical students. GenPsychiatry.5 (Suppl 1): S149. doi: 10.1186 / 1744-859X-5-S1-S149

Nevid, et.al.,. (2005). AbnormalPsychology.Volume 1. Jakarta: Erland.

Rachmat. Jalaludin. (2008). Psychology ofCommunication.Bandung. PT. RemajaRosdakarya

Sander, JB, \& McCarty, CA (2005). Youth depression in the family context: Familial risk factors and models of treatment. Clinical Child and Family PsychologyReview,8 (3)

of Intercession. 2008. Role of IslamicEducation,Serang: Echoes Persada Press.

Tannous. Adel. (2011). Factors causing depression among children in Jordan: what teachers see. Procedia - Social and BehavioralSciences.30 (2011) $341-346$. 